\title{
COOPERATION, COLLABORATION AND LANGUAGE: SCIENCE AND ITS TRANSITION
}

\author{
BAMBANG HIDAYAT \\ Bosscha Observatory I.T.B. and Department of Astronomy, I.T.B. \\ Indonesia
}

Before going to the central theme it is perhaps necessary to say what science is, as opposed to other human knowledge. In a rather short statement science may be defined as a world picture, or it may be closer to the heart of the matter if it is said that science is the product of organized fantasy about the real world. Up to this point it must be hastily added that there are also many other branches in human knowledge that share the same characteristics with science. For example, experiment is thought to be peculiar to science. Actually the alchemists of the middle ages did undertake experiments. What was missing in their experiments -and only later applied by Lavoisier and other giants of science in that period-are the hypothetical-deduction methods that science multiplied. Again, observations and logic were also thought to be peculiar to science. We learned, however, the astrologers did make observations and that theologians had logic and that logic is is perhaps the most methodological component of all human inquiry. Thus, as such, one would not be able to discern science from the rest of human activities. But there are boundaries within which science can legitimately operate. The first one is that science denies two types of truth: truth by logic and truth by faith. On the other hand science accommodates only one truth. The other boundary is the constant test by internal logic of necessity and by external public record. These boundary conditions must always be observed, as otherwise one will fall into the realm of magic.

From its cradle in the western civilization science as such has been following the wave of western domination to spread all over the world. The propagation has been made possible by two principal methods, the first is due to survival of equilibrium state and the second is caused by replication of structures. On its way, as in other cases of cultural propagation, science is not excepted from the general rule. Filtering processes must then have been operating at many countless cultural borders - whether it be called adaptation, reluctance or enthusiasm -manifesting itself in the different way science progresses in the science-receiving nation. Some countries -to name a few examples, Japan and India- seem ready to absorb science, while some other Asian countries seem to be less successful in adapting it. Is there any internal cause for it that individuals and people equal in natural gifts are not dealt out equal fates by history?

A closer look at the growth of science at its origin indicates that there must have been a prerequisite, for developing science. In the first place in order to be able to accept change there must have been a preparedness for ethical mutation. Some expounded the view of the cause of scientific revolution in the west as the realization of the hedonist-libertarian ethics -ethics which provided the thinkers and philosophers of that time with the possibility to pursue their own interest and pleasure for the sake of uncovering the secret of nature. It then became more and more apparent, in later years, when science struck many interfaces with other human interests and social structures and language systems, that other factors were necessary in order to make science as it is now. One of the most demanding is the public and societal needs that have entered into the scene of science -and external forces that cannot be ignored in the science-technological atmosphere. This is also the situation that many developing countries have to deal with.

We know that progress remains in the hands of the few, integrated, scientists or bodies of science communities. Some countries may have shown that their success in developing science has been due to vast amounts of money. In reality, the progress of science was the result of intelligent use of the large amount of funds, ingenuity of the scientific communities, and the farsightedness of the policy maker with human resources. In the present model of technological society it is impossible to envisage science existing independently without public support. To obtain this support is a struggle. 
A national policy is therefore needed which can serve as foster parent for science development, and which should emphasize the promise of science for the attainment of major public objectives. By stating this, it is not the intention of the reviewer to stress the one-to-one correspondence between science and material return or productivity.

The founding of universities in Indonesia has helped to prepare the future in the sense that it accommodated the:

a. the practical transfer of science

b. scientific knowledge and information

c. the scientific attitude and approach to phenomena.

There are a selected few who have enjoyed the privilege of acquiring the western mode of education through familiarity with the English language. New information in foreign languages is abundant. Unfortunately expressing one's thoughts in a foreign language is an entirely different matter as one is hampered by the different grammar of his or her own language. For oral communication pronunciation is another obstacle. This has caused, in my opinion, difficulty in writing reports. A National curricula to improve teaching foreign languages are required. Nevertheless, the present mode of teaching has left the few practitioners open to new outside stimuli.

\section{POSTER PAPERS}

The following poster papers were accepted in connection with the Joint Discussion. Abstracts of most of them can be found in the booklet provided to participants at the General Assembly. The papers by Oswalt and Querci will appear during 1997 in the IAPPP circular.

1. Development of Astronomy Education in India, V. B. Bhatia, Department of Physics and Astrophysics, University of Delhi, Delhi-110007, India.

2.Preserving Access to Small Observatories throughout the World: The Role of University Consortia and Collaboration, T. D. Oswalt, Florida Institute of Technology, $150 \mathrm{~W}$. University Blvd, Melbourne, Florida, 32901, U.S.A.

3. The Future Suffa Radio Astronomy Observatory, A. S. Hojaev and G. I. Shanin, Uzbek State Space Research Agency, Tashkent, and Astronomical Institute, Uzbek Academy of Science, Uzbekistan.

4. The New Generation Astronomical Telescopes Project, Michael F. Bode, Liverpool John Moores University, Liverpool L3 3AF, U.K.

5. Scientific Problems for Small CCD Telescopes, O. P. Bykov, Pulkovo Astronomical Observatory, 65 Pulkovo 196140, Russia.

6. Teaching Youngsters about the Moon's Surface with Reduced Facilities, R. M. Ros, Dept. Matematica Aplicada i Telematica, Universitat Politecnica de Catalunya, Spain.

7.Astrophysical Orientation of Physics Students through Seminars in Rural Mexico, Tapan K. Chatterjee, D. Vera, R. Fourier and A. Pedroza, Facultad de Ciencias F. M., y Instituto de Ciencias, Universidad A. Puebla, Apartado Postal 1316, Puebla, Mexico.

8. Astronomy Education in Greece, M. Metaxa, Arskaeio High School and National Observatory of Athens, 63 Eth. Antistaseos, 15231, Athens, Greece.

9. The Importance of Distance Education in the Developing World, Barrie W. Jones, Astronomy Group, The Open University, Walton Hall, Milton Keynes, MK7 6AA, U.K., and Derek Mc Nally, University of London Observatory, Mill Hill Park, London, NW7 2QS, U.K.

10. About the Euro-Asian Astronomical Society, Nikolai G. Bochkarev, Sternberg Astronomical Institute, Universitetskij prosp. 13, 119899, Moscow, Russia.

11. The NORT Project, F. Querci and M. Querci, Observatoire Midi-Pyrenées, 14, Ave E.-Bélin, 31400 Toulouse, France. 